Ana Filomena Curralo anacurralo@estg.ipvc.pt Polytechnic Institute of Viana do Castelo

Vitor Quelhasvquelhas@gmail.com

Porto Polytechnic Institute

Vasco Branco vasco.branco@ua.pt

University of Aveiro

Rui Mendonça ruimendonca@fba.up.pt

University of Porto

\title{
Non-tradition as factor of creativity in Portuguese typography
}

Our purpose is to present a diachronic and synchronic overview of typeface design in Portugal, since the dawn of typography until current digital typeface design. This article also aims to contextualize typeface design main periods within the European typographic tradition.

Our findings suggest that foreign expertise and aesthetics were frequently introduced in Portugal. By the opposite, other European countries were traditionally innovative in typeface design. There were in fact surges of innovation made in Portugal, but usually by the hands of foreigners working in Portugal.

We address the Portuguese case in a global context of typeface design production. Along the history of typography until the Digital Revolution there were no outstanding singularities regarding foreign counterparts. However, the Digital Revolution brought a paradigm shift, with Portuguese designers gaining international prominence. Our results indicate that typefaces always relied on difference and on local / global interdependence. Tradition in typeface design was found non-linear and non-stationary. Instead, it was identified as an open, ever-changing process.

keywords tradition, typeface design, typography, Portugal, creativity

\section{Introduction}

"Tradition is an historical accomplishment that the designer must grow upon and yet apart from." (Beall, 1959 as cited by Heller, 1993)

This paper addresses typeface design tradition as a process in constant evolution. Conveying aesthetic and technical knowledge, its legacy builds history, upon which are revealed the most relevant local and global features.

In the history of European typography, three major landmarks may be distinguished: the Gutenberg Revolution, the Industrial Revolution and the Digital Revolution. The latter unleashed a wide range of construal operations. Some designers revised traditional methods, techniques and aesthetics, while others parted with tradition, namely in behalf of experimentation practices.

In Portugal, the Digital Revolution, internet access and open information led to the creation of a small but steady development in typeface design. 


\section{The Gutenberg Revolution}

Before Gutenberg, woodblock printing imitated the handwritten letters of the time'. Adapting the existing technologies, Gutenberg created a faster and more efficient printing system, leading to one of the most influential events in the history of mankind. Metal type pieces were more durable, and after a while, typographers began to change letterforms, finding the most suitable types for the new printing techniques.

Some of the most noteworthy typefaces were those developed in the late fifteenth century by the Venice printers Nicholas Jenson and Aldus Manutius. Jenson's typeface (1470) is round, open, stately and formal. This classical model is considered the archetype for roman-style typefaces. In 1495, Aldus developed a new font to print the works of Cardinal Bembo, the Aldine fonts, which inspired typefaces and letterforms for over 500 years.

Aldine fonts changed Italian typographic tradition, and its influence is easily found on French typography with the Garamond typefaces (1545), and in English typography with the Caslon typeface (1732). French typefaces influenced Dutch designers, such as Christopher Van Dyck (1660), supporting the notion that Caslon typeface was in fact based on the Dutch typeface.

Nevertheless, typographic design bears a wide range of interpretations concerning letterforms. This results from a tradition of shape evolution based on reworked copy of pre-existing typeface structures. Yet, although typeface structures (macro) remained constant, the formal aspect (micro) changed in several European countries such as Italy, France, Holland and England; outstanding in the history and tradition of typeface design and production.

\section{The Industrial Revolution}

During the nineteenth century, the Industrial Revolution triggered changes in technology, aesthetics and the social role of typography. The steam-powered rotary presses changed the course of typography, allowing printing on an industrial scale². A new flow of mechanical inventions allowed for a wide range of design possibilities and a sharp fall in unit costs. The need to disseminate information increased in intensity and speed all over newspapers and periodicals.

Exaggerated type proportions were introduced along with the classic Manutius, Garamond and Caslon typestyles. The apex was the creation of beefy letterforms with large stems and serifs (Fat Faces), inspired by a new wave of advertising, designed to be noticed. Typeface designers, once demanded for the excellence and aesthetics of roman-style typefaces, were requested in the new Industrial Age by clients who sought impact, strength and novelty, in order to meet the emerging advertising requirements. Excellence and heritage were outshined by differentiation, novelty and impact.

Subsequently, the Slab Serif was born between 1810 and 1815, and was home to further

\footnotetext{
Gothic style.

${ }^{2}$ In 1811, the German English König printer and inventor patented a steam-powered cylinder press. In addition to the steam printing press (1810), he later used rollers to make impression in a power-driven press (1811-1814). This machine printed 400 sheets per hour - almost twice the hand operated printing presses. Source: Febvre, Lucien; Martin, Henri-Jean (1997), The Coming of the Book: The Impact of Printing 1450-1800, London: Verso.
} 
subsets of typeface styles. Characterized by similar thickness between vertical and horizontal stems and by rectangular serifs, according to Nicolete Gray (1977) the Slab Serif is the most brilliant invention of the nineteenth century, and perhaps the most comprehensive and concise expression of the dominant culture of that period.

\section{The Digital Revolution}

Since the mid-1980's, digital technology became part of everyday life. The personal computer led to a paradigm shift that changed typeface design. In view of the new media, typefaces were adapted, reconfigured, or created from scratch. It was a period of experimentation, challenging traditional methods.

The use of layered fonts, integrating type and image, became common. New visual codes required reassessing typographic conventions. Concepts such as readability and passive reading were questioned. Multiple influence vectors and technological and aesthetic approaches became accessible to all.

Technology democratized the access to information, and also to typeface design. For the first time in history, typeface design and production left the specialized field of industry to become accessible to all with a personal computer, specific editing software - and some persistence.

Although not impervious, typefaces were relatively stable until the 1980's. This allows establishing a timeframe. After postmodernism, various short-lived movements and aesthetic trends coexisted in a frenzy of experimentalism and ambiguity.

\section{The Portuguese case}

In Portugal, typography began in the late fifteenth century. However, the Portuguese editorial market only took off in full by the beginning of the sixteenth century. Dominated by foreign printers and typographers, the technical means and printing equipment were scarce. Often worn out or in poor working conditions, imported material allowed more or less accurate printing efforts (Anselmo, 1997).

During the sixteenth century and the immediately following there were no Portuguese innovative typographers resembling the mentioned foreign ones. In fact, the introduction of roman-style typefaces in Portugal happened later than in Italy. The oldest printed work using these typefaces dates from 1540, from the monastery of the Canons Regular of the Holy Cross, in Coimbra, whose publishing work focused on national poetry (Fig. 1).

In Portugal and abroad, the sixteenth century accommodated a number of typographical dynasties, such as the Craesbeecks ${ }^{3}$ from Antwerp, established in Portugal for over a century (Dias, 1996). The graphic quality and durability of their productions was acknowledged both by their contemporaries and by the ensuing historians of books and printing in Portugal 4 . Nonetheless, they added nothing to typeface design innovation and culture. They increased editorial production implementing European trends.

${ }^{3}$ Peter Van Craesbeeck, or Pedro Craesbeek according ti his Portuguese signature, founder of the Craesbeeck family printing shop, was an apprentice at the Antwerp printing house Officina Plantiniana. ${ }^{4}$ Some of these historians were Artur Anselmo, João José Alves Dias, Pina Martins, or José Peixoto, among many others.

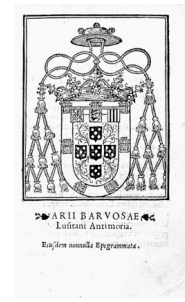

Figure 1.

Title page of Antimoria (1536) by Aires de Barbosa (1456-1530). Printed in Coimbra by Canons Regular of the Holy Cross this was the first book printed in roman typefaces. 
By the eighteenth century, typographic machinery, and printing and publishing facilities began to resemble and multiply. Until then, a small group of families monopolized the only way of disseminating the written word. In urban centres, new workspaces thrived. Yet, only the oldest, most traditional and well-reputed typographic houses remained in the service of the Portuguese Royal House and noblemen.

By that time, Jean Villeneuve designed the first book published in Portugal on the printing press. A caster and a punch-cutting engraver, he was hired to work for the Royal Academy of Portuguese History (Academia Real de História Portuguesa), signing his first printing work with typographic elements entirely produced in Portugal. It was entitled Primeira origem da arte de Imprimir dada à luz pelos primeiros characteres (First edition of the art of printing delivered by the first characters), published in Lisbon, in 1732, by the typographic house of José António da Silva, licensed editor of the Portuguese Royal Academy.

Villeneuve was commissioned to create the first Type Foundry to manufacture typefaces, matrices and other type-related equipment. However, Villeneuve types, although important in the history of Portuguese typography, did not improve any formal feature at a European level.

In the history of Portuguese typographic design there were no styles or typefaces with European impact or notoriety similar to that of countries such as Italy, France, England or Holland. The novelties and aesthetic models from these countries were simply reproduced and adapted to the Portuguese language, and to varying graphic or editorial demands.

\section{Portuguese digital typographic design}

Performing a large time leap, we intend to demonstrate how the introduction of new digital technologies; computers and later the Internet, were crucial to bridge the gap regarding foreign European countries.

The accession of Portugal to the EEC/EU in 1996 fostered a newly emerging society of welfare, leisure, mass consumption and modernization. It was a time of visual seduction, eclecticism and coexistence of different aesthetic trends. The spirit of freedom and experimentation of the new age is portrayed by the early typographic production of designers such as Mário Feliciano or Dino dos Santos (Quelhas, V.; Branco, V; Heitlinger, P., 2011).

The first typefaces designed in Portugal in the early 1990's reflect the spirit of the time. In the light of historical distance, those days may now be seen as a period of experimentation and learning. With no previous experience or knowledge, the first Portuguese type designers were self-learners navigating the typographic ocean. As an example, figure 2 depicts the impact on the early works by Mário Feliciano from the Gringe style, by the American designer David Carson.

It was a period of formal experimentation in search of greater expressivity of results. To know or not to know the history of typography in Portugal did not matter much. Portuguese roots, heritage or tradition were also outcast issues. The World Wide Web proposed a whole new constellation of desires and inspirations. However, the end of the twentieth century was marked by syncretism, demanding backing and validation for everything. According to Fragoso (2012), globalization and homogenization characterize that time.

In this second period, typeface designers went in search for accurate historical 
information. From experimental typography, based on formal issues rather than functional ones, historical searching became the ultimate goal. There was a growing interest in designing typography for texts, driven by new demands and the new available tools.

As historical searching began, several designers used local typographical memories for inspiration. But soon the information shortage led them to find roots in foreign typographical models. Foreign borrowing thus persisted as a common practice. Mário

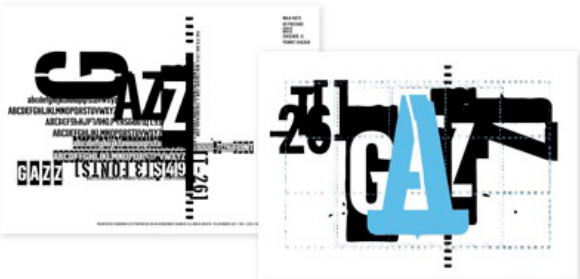

Figure 2.

Postcard promoting the font Gazz (1997.T26) by Mario Feliciano Postcard designed by Carlos Segura.

Feliciano soon switched from the national cultural heritage gap and lack of tradition onto Spanish tradition. There he found the opportunity to interpret the great Spanish typographers.

Facing the same lack of Portuguese typographic tradition, Dino dos Santos instead sought in Portuguese calligraphy the inspiration for his interpretations, creating Ventura and Andrade typefaces (Fig. 3), both internationally distinguished.

The awareness that Portugal had no tradition in the sense of a model from the past, a historical of national origin, caused many to search for inspiration in foreign models These authors endeavoured to contribute towards typographic history, remaining embedded in the Portuguese culture. This is the archetypal Portuguese way of making - canvasing and readjusting the apparent foreignness, while exacerbating regionalisms, as figure 2 demonstrates. In the first decade of the twenty-first century, Portuguese font families dominated the Portuguese typographical market in response to editorial demands. Technological barriers to experimentation were broken, coming to terms with a typographic past filled with questioning and foreign borrowing.

In addition to the established Mario Feliciano and Dino dos Santos, other designers and concerns emerged. Ricardo Santos is a remarkable example, designing and creating several typefaces, including Lisboa font family (Fig. 4).

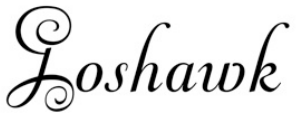

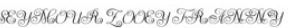

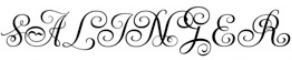
my hard nose, glass jaw, and soft heart $18471965 \& 2003$ đype Quiz Sbocks Faux Oblique
Visigoths The land of kings and fishermen Stellar exploits Dangerous seafaring

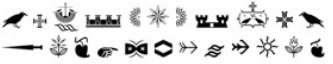

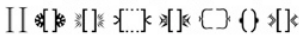

Figure 3 (left). Andrade Pro Script (2006) by Dino dos Santos

Figure 4 (right) Lisboa (2005) by Ricardo Santos.

This designation points toward local inspiration, as corroborated by the dingbats. However, despite the functionalist character, this large font family comprises distinctive calligraphic mannerisms from several southern Europe cultures. In fact, the humanistic features of the shapes take Lisboa away from 'nomenclature 
nostalgia', onto a 'multicultural Atlantic stance'. In fact, as advocated by Jorge dos Reis', typefaces are not bound to our culture. Instead, they are interspersed.

\section{Conclusion}

Throughout history, typefaces were replicated and copied by Portuguese and foreign typographers at different times. During periods of major typographic development, as the identified revolutions, the concept of tradition was based on aesthetic and material longevity, through technical reproductions enhancing originality and historical testimony. The Digital Revolution paradigm allowed typographic designers to create their own tradition. Technological methods shortened space-time relationship and changed the understanding of dissemination of knowledge through contagion by proximity.

The lack of continuity in graphic tradition reveals a lack of national typographic identity, which may be considered a characterizing trait. However, the Digital Revolution changed this scenario and there is now a group of internationally recognized Portuguese typeface designers.

Therefore, despite the absence of a so-called national tradition - or perhaps because of that - they were driven to produce and innovate in typeface design, with new forms, detached from previous stereotypes; a form of hybridism or métissage that in fact characterizes the whole Portuguese history of typography and typeface design.

\section{References}

Anselmo, A. (1997) Estudos da História do Livro, Lisboa: Guimarães Editores.

Dias, J. (1996) Craesbeeck: Uma dinastia de impressores em Portugal: Elementos para o seu estudo. Lisboa: Associação Portuguesa de Livreiros Alfarrabistas.

Febvre, L.; Henri-Jean, M. (1997)The Coming of the Book: The Impact of Printing 1450-1800. London: Verso.

Fragoso, M. (2012) Design gráfico em Portugal. Lisboa: Livros Horizonte.

Gray, N. (1976) Nineteenth Century Ornamented Typefaces. Oxford: Faber and Faber Limited. Heller, S. (1993) Who says classical has to mean boring?. In Eye Magazine, 3(11). Retrieved January 10, 2014, from http://www.eyemagazine.com/opinion/article/monitor6 Heller, S.; Fili, L. (1999)Typology: Typeface design from the Victorian era to the digital era. San Francisco: Chronicle books.

Quelhas, V.; Branco, V.; Heitlinger, P. (2011) The languages of Typeface Design in Portugal. Strategic Design Research Journal, 4(2), 84-92.

\section{Acknowledgements}

This work is funded by national funds through the Foundation for Science and Technology - FCT - in the scope of project PEst-OE/EAT/UI4057/2014.

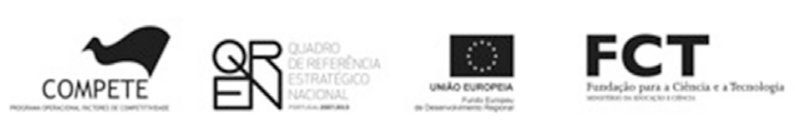

